FAKTOR-FAKTOR YANG MEMPENGARUHI PEMBERDAYAAN DIRI DALAM MENGONTROL KADAR GULA DARAH PADA PENDERITA DIABETES MELLITUS DI DESA MUNDU PESISIR KEC. MUNDU KAB. CIREBON

\author{
Yani Nurhayani ${ }^{1}$, Titin Supriatin ${ }^{2}$ \\ 1,2Dosen Program Studi DIII Keperawatan STIKes Ahmad Dahlan Cirebon \\ E-mail: yani.nurhayanii123@gmail.com
}

\begin{abstract}
FACTORS INFLUENCING THE SELF-EMPOWERMENT IN CONTROLLING BLOOD SUGAR LEVELS IN DIABETES MELLITUS PATIENTS IN MUNDUPESISIR VILLAGE, MUNDU DISTRICT, CIREBON REGENCY
\end{abstract}

Background: Diabetes mellitus is a disease characterized by a set of symptoms caused by a decrease in insulin secretion or a decrease in insulin sensitivity. This condition increases blood sugar levels. Efforts to improve the self-empowerment of patients with diabetes mellitus must understand the factors that influence the process of self-empowerment of each patient with diabetes mellitus. To be maximized by patients with diabetes mellitus to have good self-empowerment. Objective: To identify the factors that influence self-empowerment in controlling blood sugar levels in people with diabetes mellitus.

Research Methods: this type of research is descriptive with a retrospective study approach. The subjects of this study were patients with diabetes mellitus, totaling 32 respondents. Collecting data using questionnaires distributed to respondents. Self-empowerment was measured using the Diabetes mellitus Empowerment Scale (DES) questionnaire. Data analysis was univariate using frequency distribution and bivariate using chi-square.

Research Results: There is a significant relationship in education factor with self-empowerment of diabetes mellitus patients ( $p$-value $=0.006,=0.05$ ). While the factors that did not have a significant relationship were gender, age, length of suffering from diabetes mellitus, knowledge, income, and family support ( $p$ value $>a$ ).

Conclusion: There is a significant relationship in the education factor and while the factors that do not have a significant relationship are gender, age, duration of suffering from diabetes mellitus, knowledge, income, and family support. Suggestions in this study are further researchers can provide education that can increase the self-empowerment of diabetes mellitus patients.

Keywords: self-empowerment, diabetes mellitus 


\section{INTISARI: FAKTOR-FAKTOR YANG MEMPENGARUHI PEMBERDAYAAN DIRI DALAM MENGONTROL KADAR GULA DARAH PADA PENDERITA DIABETES MELLITUS DI DESA MUNDU PESISIR KEC MUNDU KABUPATEN CIREBON}

Latar Belakang: Diabetes mellitus merupakan suatu penyakit dengan ditandai dengan sekumpulan gejala yang disebabkan oleh penurunan sensitivitas insulin atau penurunan sekresi insulin. Keadaan ini mengakibatkan peningkatan kadar gula darah. Upaya meningkatkan pemberdayaan diri pasien diabetes mellitus, harus memahami tentang faktor-faktor yang mempengaruhi proses pemberdayaan diri setiap pasien diabetes mellitus. Agar dapat dimaksimalkan oleh pasien diabetes mellitus untuk memiliki pemberdayaan diri yang baik.

Tujuan: Teridentifikasi faktor-faktor yang mempengaruhi pemberdayaan diri dalam mengontrol kadar gula darah pada penderita diabetes mellitus.

Metode Penelitian: jenis penelitian deksriptif dengan pendekatan retrospective studi. Subjek penelitian ini adalah pasien diabetes mellitus yang berjumlah 32 responden. Pengambilan data menggunakan kuisioner yang dibagikan kepada responden. Pemberdayaan diri diukur menggunakan kuisioner Diabetes mellitus Empowerment Scale (DES). Analisis data secara univariat menggunakan distribusi frekuensi dan bivariat menggunakan chi square.

Hasil penelitian: Terdapat hubungan signifikan dalam faktor pendidikan dengan pemberdayaan diri pasien diabetes melitus ( $p$ value $=0,006, \alpha=0,05$ ). Sedangkan faktor yang tidak mempunyai hubungan yang signifikan adalah jenis kelamin, usia, lama menderita diabetes melitus, pengetahuan, pendapatan dan dukungan keluarga ( $p$ value $>a)$.

Kesimpulan: Terdapat hubungan signifikan dalam faktor pendidikan dan sedangkan faktor yang tidak mempunyai hubungan yang signifikan adalah jenis kelamin, usia, lama menderita diabetes melitus, pengetahuan, pendapatan dan dukungan keluarga. Saran dalam penelitian ini adalah peneliti selanjutnya dapat memberikan edukasi yang dapat meningkatkan pemberdayaan diri pasien diabetes melitus.

Kata Kunci : pemberdayaan diri, diabetes mellitus

\section{Pendahuluan}

Diabetes mellitus adalah penyakit kronis progresif yang ditandai dengan ketidakmampuan tubuh untuk melakukan pemecahan metabolisme karbohidrat, lemak dan protein, sehingga tubuh mengalami hiperglikemia atau kadar gula darah tinggi (Black \& Hawk, 2014). Kadar gula tinggi atau hiperglikemia ditandai dengan kadar gula sewaktu $>200 \mathrm{mg} / \mathrm{dl}$, kadar gula puasa $>126$ $\mathrm{mg} / \mathrm{dl}$ (tidak ada asupan kalori selama 8 jam), 2 jam postprandial $>200 \mathrm{mg} / \mathrm{dl}$ (Lemone, et all, 2016). Diabetes mellitus pada tahun 2019 prevalensi di dunia terjadi pada rentang umur 20-79 tahun dengan jumlah 463 juta orang (9,3\%). Pada tahun 2030 diperkirakan akan mengalami peningkatan dengan jumlah 578 juta orang dan pada tahun 2045 dengan jumlah 700 juta orang. 10 negara prevalensi tertinggi di dunia adalah Negara China 116,4 juta orang dan terendah adalah Negara Bangladesh 8,4 juta orang. Negara Indonesia urutan ke-7 dari 10 negara tertinggi dengan jumlah 10,7 juta orang dengan diabetes mellitus (IDF, 2019).

Prevalensi diabetes melitus pada tahun 2018 di Indonesia berdasarkan diagnosis dokter pada umur $\geq 15$ tahun sebesar $2 \%$. Prevalensi diabetes melitus pada umur $\geq 15$ tahun sebesar 
$2 \%$ mengalami peningkatan dibandingkan tahun 2013 hanya sebesar 1,5\%. Namun, prevalensi diabetes mellitus berdasarkan hasil pemeriksaan kadar gula darah pada tahun 2013 sebesar 6,9\% menjadi 8,5\% pada tahun 2018 (Riskesdas, 2018). Prevalensi diabetes mellitus tertinggi di Indonesia pada tahun 2018 yaitu Provinsi DKI Jakarta sebesar 3,1\%, dan terendah yaitu Nusa Tenggara Timur sebesar $0,9 \%$, sedangkan Provinsi Jawa Barat sebesar 1,7\% mendapat urutan ke-17 dari 33 Provinsi, (Kemkes RI, 2019).

Prevalensi tertinggi diabetes mellitus di Provinsi Jawa Barat tahun 2018 terdapat di 27 Kabupaten Kota yaitu Bogor sebesar 1,73\% dan terendah yaitu Kota Banjar sebesar 0,95\%, sedangkan Kabupaten Cirebon menempati urrtan ke-9 sebesar 1,18\% (Riskesdas, 2018).

Uraian insiden diabetes mellitus diatas dapat mengakibatkan manisfestasi klinis dampak kesehatan yaitu banyak minum, banyak makan, sering kencing, lemas, berat badan menurun, luka yang sulit sembuh, gatal, kesemutan dan sampai kesadaran menurun. Oleh karena itu harus dilakukan penatalaksanaan yang dapat mengatasi diabetes mellitus. Penderita yang telah terdiagnosa harus dikelola dengan baik agar dapat mengendalikan kadar gula darah. Penyakit diabetes mellitus ini tidak dapat disembuhkan tetapi kadar gula darahnya dapat dikendalikan (Suyono dkk, 2015). Menurut Tarwoto, 2012, penderita diabetes mellitus dapat mengontrol kadar gula darah dalam batas normal adalah dengan melakukan aktifitas manajemen diabetes mellitus. Terdapat lima pilar pengelolaan diabetes mellitus tipe 2 yaitu pengaturan pola makan (diet DM), aktifitas fisik (olahraga), monitoring kadar gula darah, minum obat untuk mencegah hipoglikemik dan penyuluhan/ edukasi.
Selain dari lima pilar diatas, usaha yang harus dilakukan oleh perawat sebagai petugas kesehatan yaitu meningkatkan pemberdayaan diri terhadap penderita diabetes mellitus agar dapat mengontrol kadar gula darah. Menjaga kadar gula darah tetap stabil menunjukkan angka kejadian komplikasi diabetes mellitus yang lebih rendah (Suyono, dkk, 2015). Memberdayakan pasien berarti memberikan mereka kesempatan dan lingkungan untuk mengembangkan keterampilan, kepercayaan diri dan pengetahuan untuk bergerak dari penerima pasif perawatan untuk menjadi mitra aktif dalam perawatan kesehatan mereka (Wong \& Riege, 2012). Menurut Anderson et all, 2003 dalam Nuari, 2014 pemberdayaan diri (self empowerment) yaitu kemampuan dan tanggung jawab individu mengontrol hidup mereka sendiri dan menentukan pilihan dalam melakukan perawatan pada penyakitnya untuk meningkatkan status kesehatan.

Meningkatkan pemberdayaan diri atau self empowerment pasien diabetes mellitus tipe II, seorang perawat harus melakukan tindakan dengan berbagai pendekatan. Hal ini sesuai dengan hasil penelitian yang telah dilakukan oleh Nuari \& Kartikasari, 2016, mengenai peningkatan self empowerment dan kualitas hidup pasien diabetes mellitus tipe II dengan pendekatan diabetes mellitus empowerment education (DEE) berbasis health promotion model yang dilakukan pada 32 responden di Wilayah Kerja Puskesmas Bendo Pare Kediri menunjukkan bahwa ada perbedaan self empowerment dan kualitas hidup pasien diabetes mellitus melitus tipe II sesudah perlakuan. Didapatkan hasil $P v<0,05$, terdapat pengaruh terhadap self empowerment dan kualitas hidup.

Seorang perawat tidak hanya melakukan intervensi berbagai 
pendekatan dalam meningkatkan pemberdayaan diri (self empowerment) pada pasien diabetes mellitus tipe 2, tetapi juga harus memahami tentang faktor-faktor yang mempengaruhi self empowerment setiap penderita diabetes mellitus. Faktor-faktor tersebut sangat penting dalam menganalisis faktor yang mampu dimaksimalkan oleh penderita diabetes mellitus agar mempunyai pemberdayaan diri yang baik. Seperti pada penelitian yang telah dilakukan Nuari, 2014, mengenai Analisis Korelasi personal factor, perceived benefits of action, perceived barrier to action dengan Pemberdayaan Diri Pasien Diabetes Mellitus Tipe II Berbasis Teori Health Promotion Model menunjukkan bahwa hubungan yang signifikan dalam faktor usia, pendidikan, penghasilan dan lama menderita diabetes mellitus mellitus, perceived benefits of action, perceived barrier to action dengan self empowerment pada pasien diabetes mellitus tipe II, sedangkan jenis kelamin tidak terdapat hubungan yang signifikan dengan self empowerment pada pasien diabetes mellitus tipe II. Penelitian serupa yang telah dilakukan oleh Tol, et all, 2013, mengenai Empowerment Assessment and Influential Factors among Patients with Type 2 Diabetes mellitus menunjukkan bahwa terdapat hubungan yang signifikan antara usia dan subscale "menilai ketidakpuasan dan kesiapan untuk mengubah" dan "pengaturan dan mencapai tujuan diabetes mellitus" dan terdapat hubungan yang signifikan antara lamanya penyakit diabetes mellitus dengan subscale "menilai ketidakpuasan dan kesiapan untuk perubahan". Kesimpulannya adalah pasien dengan diabetes mellitus tipe 2 memiliki potensi untuk diberdayakan untuk mengelola penyakit kronis mereka jika mereka secara aktif menerima informasi dan pendidikan.

Penderita diabetes mellitus yang memiliki pemberdayaan diri (self empowerment) yang kurang biasanya disebabkan dari kurangnya adaptasi terhadap kondisi penyakitnya. Kadar gula darah yang tidak terkontrol menyebabkan kondisi psikologisnya tidak stabil. Psikologis dan tekanan emosional merupakan masalah dalam kehidupan sehari-hari pada penderita diabetes mellitus. Penderita diabetes mellitus sering merasa cemas dengan perubahan kebiasaan makan, rasa takut dan khawatir tentang kemungkinan komplikasi lanjutan serta ancaman hipoglikemia dan hiperglikemia (Booker et al, 2008 dalam Ho, et all, 2010). Penderita diabetes mellitus harus mempunyai permberdayaan diri agar individu dapat mengidentifikasi dan memecahkan masalahnya secara mandiri. Pasien diabetes mellitus dapat membuat keputusan apa yang akan dimakan, kapan melakukan latihan jasmani dan bagaimana minum obat untuk mengendalikan glukosa darah.

Berdasarkan hasil wawancara pada pengambilan data dan studi pendahuluan yang peneliti lakukan di Desa Mundu Pesisir, didapatkan data yaitu 2 orang penderita diabetes melitus mengaku belum dapat mengatur pola makan, 2 orang masih bisa beradaptasi secara psikososial, 1 orang merasa tidak puas dan belum siap untuk mengubah konsep perawatan diabetes mellitus. Kelima penderita mengaku belum memiliki pemberdayaan diri dalam mengontrol kadar gula darah. Dapat disimpulkan bahwa sebagian besar pasien yang belum dapat mengontrol gula darah memiliki pemberdayaan diri (self empowerment) yang rendah.

Penelitian ini bertujuan mengidentifikasi faktor-faktor yang mempengaruhi pemberdayaan diri dalam mengontrol kadar gula darah 
pada penderita diabetes mellitus di Desa Mundu Pesisir Kec Mundu Kab Cirebon Tahun 2021.

\section{METODOLOGI}

Penelitian ini menggunakan jenis penelitian deksriptif dengan pendekatan retrospective studi. Subjek penelitian ini adalah pasien diabetes mellitus yang berjumlah 32 responden. Pengambilan data menggunakan kuisioner tentang variabel independen dan variabel dependen. Pemberdayaan diri diukur menggunakan kuisioner Diabetes mellitus Empowerment Scale (DES). Analisis data secara univariat menggunakan distribusi frekuensi dan bivariat menggunakan chi square.

Variabel independen meliputi Jenis Kelamin, Usia, Tingkat Pendidikan, Lamanya penyakit, pengetahuan, pendapatan, dukungan keluarga. Variabel Dependen meliputi Nilai keseluruhan dari semua subscale pemberdayaan diri (self empowerment). Pengambilan data dilakukan mulai tanggal 5 Januari s.d 2 Februari 2021.

\section{HASIL DAN PEMBAHASAN}

1. Distribusi responden berdasarkan Jenis kelamin, Usia, Pendidikan, Lama Menderita Diabetes Mellitus, Pengetahuan, Pendapatan dan Dukungan Keluarga

\begin{tabular}{llcc}
\hline \hline No & \multicolumn{1}{c}{ Variabel } & $\mathbf{n}$ & $\%$ \\
\hline & Jenis Kelamin & & \\
1 & Laki-laki & 11 & 34,4 \\
2 & Perempuan & 21 & 65,6 \\
\hline \multicolumn{4}{l}{ Usia } \\
\hline 1 & $0-19$ Tahun & - & - \\
2 & 20-39 Tahun & 8 & 25,0 \\
3 & $40-59$ Tahun & 21 & 65,6 \\
4 & $60 \quad$ Tahun & 3 & 9,4 \\
& keatas & & \\
\hline & Pendidikan & & \\
1 & Tidak Sekolah & 1 & 3,1 \\
2 & SD & 14 & 43,8 \\
3 & SMP & 12 & 37,5 \\
4 & SMA & 3 & 9,4
\end{tabular}

\begin{tabular}{clcc}
5 & PT & 2 & 6,3 \\
\hline & Lama & & \\
& Menderita DM & & \\
1 & $<5$ tahun & 14 & 43,8 \\
2 & 5-10 tahun & 16 & 50,0 \\
3 & $>10$ tahun & 2 & 6,3 \\
\hline & Pendapatan & & \\
1 & $<1$ Juta & 21 & 65,6 \\
2 & 1 - 3 Juta & 11 & 34,4 \\
3 & 3 - 5 Juta & - & - \\
4 & 5 Juta keatas & - & - \\
\hline & Pengetahuan & & \\
1 & Kurang Baik & 13 & 40,6 \\
2 & Baik & 19 & 59,4 \\
\hline & Dukungan & & \\
& Keluarga & & \\
1 & Kurang Baik & 9 & 28,1 \\
2 & Baik & 23 & 71,9 \\
\hline & Pemberdayaa & & \\
& n Diri & & \\
1 & Kurang Baik & 11 & 34,4 \\
2 & Baik & 21 & 65,6 \\
\hline & Jumlah & 32 & 100,0
\end{tabular}

Berdasarkan tabel diatas, menggambarkan bahwa responden yang berjenis kelamin laki-laki sebanyak 11 orang $(34,4 \%)$ dan berjenis kelamin perempuan 21 orang (65,6 \%). Dapat disimpulkan bahwa responden lebih banyak jenis kelamin perempuan dari pada laki-laki. Responden yang memiliki umur pada rentang 20-39 tahun sebanyak 8 orang $(25,0 \%)$, umur pada rentang $40-59$ tahun sebanyak 21 orang $(65,6 \%)$ dan umur pada rentang 60 tahun keatas sebanyak 3 orang $(9,4 \%)$. Dapat disimpulkan bahwa responden lebih banyak berumur pada rentang 40-59 tahun. Sebagian besar responden yang mempunyai pendidikan SD yaitu sebanyak 14 orang (43,8\%), sedangkan untuk pendidikan tidak sekolah, SMP, SMA dan PT yaitu masing-masing 1 orang $(3,1 \%), 12$ orang $(37,5 \%), 3$ orang $(9,4 \%)$ dan 2 orang $(6,3 \%)$. Dapat disimpulkan bahwa sebagian besar responden berpendidikan SD. Sebagian besar responden yang menderita diabetes mellitus 5 s.d 10 tahun yaitu 16 orang 
$(50,0 \%)$, sedangkan untuk kurang dari 5 tahun dan lebih dari 10 tahun yaitu masing-masing 14 orang $(43,8 \%)$ dan 2 orang (6,3\%). Dapat disimpulkan bahwa sebagian besar responden menderita diabetes mellitus 5-10 tahun. sebagian besar responden yang mempunyai pendapatan $<1$ juta yaitu 21 orang $(65,6 \%)$, sedangkan untuk pendapatan 1-3 juta yaitu 11 orang $(34,4 \%)$. Dapat disimpulkan bahwa sebagian besar responden yang mempunyai pendapatan < 1 juta. Sebagian besar pengetahuan responden baik sebanyak 19 orang $(59,4 \%)$ dan kurang baik sebanyak 13 orang (40,6 \%). Dapat disimpulkan bahwa pengetahuan responden sebagian besar yaitu baik. Sebagian besar dukungan keluarga responden baik sebanyak 23 orang (71,9\%) dan kurang baik sebanyak 9 orang $(28,1$ \%). Dapat disimpulkan bahwa dukungan keluarga responden sebagian besar yaitu baik. Sebagian besar pemberdayaan diri responden baik sebanyak 21 orang $(65,6 \%)$ dan kurang baik sebanyak 11 orang $(34,4$ \%). Dapat disimpulkan bahwa pemberdayaan diri responden sebagian besar yaitu baik.

2. Hubungan Jenis Kelamin dengan Pemberdayaan Diri pada Pasien Diabetes Mellitus

\begin{tabular}{cccccccc}
\hline \multirow{3}{*}{ Jenis Kelamin } & \multicolumn{4}{c}{ Pemberdayaan Diri } & \multicolumn{2}{c}{ Total } & \multirow{2}{*}{$\mathrm{P}$} \\
\cline { 2 - 7 } & \multicolumn{2}{c}{ Kurang Baik } & \multicolumn{2}{c}{ Baik } & \multicolumn{2}{c}{ value } \\
\cline { 2 - 7 } & $\mathrm{N}$ & $\%$ & $\mathrm{~N}$ & $\%$ & $\mathrm{~N}$ & $\%$ & \\
\hline Laki-laki & 3 & 27,3 & 8 & 72,7 & 11 & 100 & 0,703 \\
\hline Perempuan & 8 & 38,1 & 13 & 61,9 & 21 & 100 & \\
\hline \multicolumn{1}{c}{ Jumlah } & 11 & 34,4 & 21 & 65,6 & 32 & 100 & \\
\hline
\end{tabular}

Berdasarkan tabel diatas menggambarkan bahwa $13(61,9 \%)$ responden yang berjenis kelamin perempuan memiliki pemberdayaan diri baik. Hasil uji chi square didapatkan $\mathrm{p}$ value > a maka Ho diterima. Hal ini menunjukkan bahwa tidak terdapat hubungan yang signifikan antara jenis kelamin dengan pemberdayaan diri $(p$ value $=0,703, a=0,05)$.

3. Hubungan Usia dengan Pemberdayaan Diri pada Pasien Diabetes Mellitus

\begin{tabular}{|c|c|c|c|c|c|c|c|}
\hline \multirow{3}{*}{ Usia } & \multicolumn{4}{|c|}{ Pemberdayaan Diri } & \multirow{2}{*}{\multicolumn{2}{|c|}{ Total }} & \multirow{3}{*}{$\begin{array}{c}\mathrm{P} \\
\text { value }\end{array}$} \\
\hline & \multicolumn{2}{|c|}{ Kurang Baik } & \multicolumn{2}{|c|}{ Baik } & & & \\
\hline & $\mathrm{N}$ & $\%$ & $\mathrm{~N}$ & $\%$ & $\mathrm{~N}$ & $\%$ & \\
\hline 20-39 Tahun & 2 & 25,0 & 6 & 75,0 & 8 & 100 & 0,796 \\
\hline 40-59 Tahun & 8 & 38,1 & 13 & 61,9 & 21 & 100 & \\
\hline 60 Tahun Keatas & 1 & 33,3 & 2 & 66,7 & 3 & 100 & \\
\hline Jumlah & 11 & 34,4 & 21 & 65,6 & 32 & 100 & \\
\hline
\end{tabular}

Berdasarkan tabel diatas menggambarkan bahwa $13(61,9 \%)$ responden yang berumur 40-59 tahun memiliki pemberdayaan diri baik. Hasil uji chi square didapatkan $\mathrm{p}$ value $>$ a maka Ho diterima. Hal ini menunjukkan bahwa tidak terdapat hubungan yang signifikan antara usia dengan pemberdayaan diri ( $p$ value $=0,796, a=0,05)$. 
4. Hubungan Tingkat Pendidikan dengan Pemberdayaan Diri pada Pasien Diabetes Mellitus

\begin{tabular}{|c|c|c|c|c|c|c|c|}
\hline \multirow{3}{*}{ Tingkat Pendidikan } & \multicolumn{4}{|c|}{ Pemberdayaan Diri } & \multirow{2}{*}{\multicolumn{2}{|c|}{ Total }} & \multirow{3}{*}{$\begin{array}{c}\mathrm{P} \\
\text { value }\end{array}$} \\
\hline & \multicolumn{2}{|c|}{ Kurang Baik } & \multicolumn{2}{|c|}{ Baik } & & & \\
\hline & $\mathrm{N}$ & $\%$ & $\mathrm{~N}$ & $\%$ & $\mathrm{~N}$ & $\%$ & \\
\hline Rendah & 7 & 25,9 & 20 & 74,1 & 27 & 100 & 0,006 \\
\hline Tinggi & 4 & 80,0 & 1 & 20,0 & 5 & 100 & \\
\hline Jumlah & 11 & 34,4 & 21 & 65,6 & 32 & 100 & \\
\hline
\end{tabular}

Berdasarkan tabel diatas menggambarkan bahwa sebagian besar responden yang berpendidikan rendah memiliki pemberdayaan diri baik yaitu sebanyak 20 orang (74,1\%). Hasil uji chi square didapatkan $p$ value < a maka Ho ditolak. Hal ini menunjukkan bahwa terdapat hubungan yang signifikan antara tingkat pendidikan dengan pemberdayaan diri ( $p$ value $=0,006, a=0,05)$.

5. Hubungan Lama Menderita DM dengan Pemberdayaan Diri pada Pasien Diabetes Mellitus

\begin{tabular}{|c|c|c|c|c|c|c|c|}
\hline \multirow{3}{*}{ Lama Menderita DM } & \multicolumn{4}{|c|}{ Pemberdayaan Diri } & \multirow{2}{*}{\multicolumn{2}{|c|}{ Total }} & \multirow{3}{*}{$\begin{array}{c}\mathrm{P} \\
\text { value }\end{array}$} \\
\hline & \multicolumn{2}{|c|}{ Kurang Baik } & \multicolumn{2}{|c|}{ Baik } & & & \\
\hline & $\mathrm{N}$ & $\%$ & $\mathrm{~N}$ & $\%$ & $\mathrm{~N}$ & $\%$ & \\
\hline$<5$ Tahun & 7 & 50,0 & 7 & 50,0 & 14 & 100 & 0,151 \\
\hline 5-10 Tahun & 4 & 25,0 & 12 & 75,0 & 16 & 100 & \\
\hline 10 Tahun Ketas & 0 & 0,0 & 2 & $\begin{array}{c}100 \\
0\end{array}$ & 2 & 100 & \\
\hline Jumlah & 11 & 34,4 & 21 & 65,6 & 32 & 100 & \\
\hline
\end{tabular}

Berdasarkan tabel diatas menggambarkan bahwa 12 orang $(75,0 \%)$ responden yang telah lama menderita diabetes melitus 5-10 tahun memiliki pemberdayaan diri baik. Hasil uji chi square didapatkan $\mathrm{p}$ value > a maka Ho diterima. Hal ini menunjukkan bahwa tidak terdapat hubungan yang signifikan antara lama menderita diabetes melitus dengan pemberdayaan diri ( $p$ value $=0,151, a=$ $0,05)$.

6. Hubungan Pengetahuan dengan Pemberdayaan Diri pada Pasien Diabetes Mellitus

\begin{tabular}{|c|c|c|c|c|c|c|c|}
\hline \multirow{3}{*}{ Pengetahuan } & \multicolumn{4}{|c|}{ Pemberdayaan Diri } & \multirow{2}{*}{\multicolumn{2}{|c|}{ Total }} & \multirow{3}{*}{$\begin{array}{c}P \\
\text { value }\end{array}$} \\
\hline & \multicolumn{2}{|c|}{ Kurang Baik } & \multicolumn{2}{|c|}{ Baik } & & & \\
\hline & $\mathrm{N}$ & $\%$ & $\mathrm{~N}$ & $\%$ & $\mathrm{~N}$ & $\%$ & \\
\hline Kurang baik & 3 & 23,1 & 10 & 76,9 & 13 & 100 & 0,450 \\
\hline Baik & 8 & 42,1 & 11 & 57,9 & 19 & 100 & \\
\hline Jumlah & 11 & 34,4 & 21 & 65,6 & 32 & 100 & \\
\hline
\end{tabular}

Berdasarkan tabel diatas menggambarkan bahwa 11 orang (57,9\%) responden yang memiliki pengetahuan baik dan memiliki pemberdayaan diri baik. Hasil uji chi square didapatkan $\mathrm{p}$ value > a maka Ho diterima. Hal ini menunjukkan bahwa tidak terdapat hubungan yang signifikan antara pengetahuan dengan pemberdayaan diri $(p$ value $=0,450, \alpha=0,05)$. 
7. Hubungan Pendapatan dengan Pemberdayaan Diri pada Pasien Diabetes Mellitus

\begin{tabular}{|c|c|c|c|c|c|c|c|}
\hline \multirow{3}{*}{ Pendapatan } & \multicolumn{4}{|c|}{ Pemberdayaan Diri } & \multirow{2}{*}{\multicolumn{2}{|c|}{ Total }} & \multirow{3}{*}{$\begin{array}{c}P \\
\text { value }\end{array}$} \\
\hline & \multicolumn{2}{|c|}{ Kurang Baik } & \multicolumn{2}{|c|}{ Baik } & & & \\
\hline & $\mathrm{N}$ & $\%$ & $\mathrm{~N}$ & $\%$ & $\mathrm{~N}$ & $\%$ & \\
\hline$<1$ juta & 10 & 47,6 & 11 & 52,4 & 21 & 100 & 0,074 \\
\hline 1-3 juta & 1 & 9,1 & 10 & 90,9 & 11 & 100 & \\
\hline 3 juta keatas & - & - & - & - & - & - & \\
\hline Jumlah & 11 & 34,4 & 21 & 65,6 & 32 & 100 & \\
\hline
\end{tabular}

Berdasarkan tabel diatas menggambarkan bahwa 11 orang $(52,4 \%)$ responden yang berpendapatan < 1 juta memiliki pemberdayaan diri baik. Hasil uji chi square didapatkan $\mathrm{p}$ value > a maka Ho diterima. Hal ini menunjukkan bahwa tidak terdapat hubungan yang signifikan antara pendapatan dengan pemberdayaan diri $(p$ value $=0,074, \alpha=0,05)$.

8. Hubungan Dukungan Keluarga dengan Pemberdayaan Diri pada Pasien Diabetes Mellitus

\begin{tabular}{|c|c|c|c|c|c|c|c|}
\hline \multirow{3}{*}{ Dukungan Keluarga } & \multicolumn{4}{|c|}{ Pemberdayaan Diri } & \multirow{2}{*}{\multicolumn{2}{|c|}{ Total }} & \multirow{3}{*}{$\begin{array}{c}P \\
\text { value }\end{array}$} \\
\hline & \multicolumn{2}{|c|}{ Kurang Baik } & \multicolumn{2}{|c|}{ Baik } & & & \\
\hline & $\mathrm{N}$ & $\%$ & $\mathrm{~N}$ & $\%$ & $\mathrm{~N}$ & $\%$ & \\
\hline Kurang baik & 5 & 55,6 & 4 & 44,4 & 9 & 100 & 0,213 \\
\hline Baik & 6 & 26,1 & 17 & 73,9 & 23 & 100 & \\
\hline Jumlah & 11 & 34,4 & 21 & 65,6 & 32 & 100 & \\
\hline
\end{tabular}

Berdasarkan tabel diatas menggambarkan bahwa 17 orang $(73,9 \%)$ responden yang memiliki dukungan keluarga baik dan memiliki pemberdayaan diri baik. Hasil uji chi square didapatkan $\mathrm{p}$ value > a maka Ho diterima. Hal ini menunjukkan bahwa tidak terdapat hubungan yang signifikan antara dukungan keluarga dengan pemberdayaan diri ( $p$ value $=0,213, a=0,05)$.

1. Hubungan Jenis Kelamin dengan Pemberdayaan Diri pada Pasien Diabetes Mellitus

Berdasarkan hasil penelitian yang telah dilakukan peneliti terhadap penderita diabetes mellitus di Desa Mundu Pesisir Kec Mundu Kab Cirebon bahwa sebagian responden berjenis kelamin perempuan 21 orang $(65,6 \%)$. Penelitian ini sejalan dengan penelitian yang telah dilakukan oleh Nuari, 2014, sebagian besar responden perempuan sebanyak 30 orang $(93,7 \%)$ dan responden lakilaki sebanyak 2 orang $(6,3 \%)$.

Berdasarkan hasil uji chi square didapatkan $\mathrm{p}$ value $>$ a maka $\mathrm{Ho}$ diterima. Hal ini menunjukkan bahwa tidak terdapat hubungan yang signifikan antara jenis kelamin dengan pemberdayaan diri pasien diabetes melitus ( $p$ value $=0,703, a=0,05)$. Hasil analisis peneliti, perbedaan jenis kelamin yaitu perempuan dan lakilaki, tidak mempengaruhi pemberdayaan seseorang dalam mencari perawatan dan pengobatan penyakit yang dideritanya.

2. Hubungan Usia dengan Pemberdayaan Diri pada Pasien Diabetes Mellitus

Hasil penelitian ini menunjukkan bahwa sebagian besar responden memiliki umur pada rentang 40-59 
tahun sebanyak 21 orang $(65,6 \%)$. Sejalan dengan penelitian yang telah dilakukan Nuari, 2014, bahwa sebagian besar responden mempunyai usia 51-60 tahun sebanyak 17 orang $(53,1 \%)$. Umur sangat erat kaitannya dengan kenaikan kadar gula darah, sehingga semakin meningkatnya umur maka prevalensi diabetes melitus semakin tinggi. WHO menyatakan setelah usia 30 tahun, maka kadar gula darah akan naik 1-2 $\mathrm{mg} / \mathrm{dL} /$ tahun pada saat puasa akan naik $5,6-13 \mathrm{mg} / \mathrm{dL}$ pada 2 jam setelah makan (Suyono, 2011 dalam Nuari, 2015). Diabetes Melitus banyak diderita oleh orang dewasa berusia diatas 40 tahun. Proses bertambahnya usia juga mempengaruhi homeostasis tubuh, termasuk perubahan fungsi sel beta pankreas yang menghasilkan insulin dan menyebabkan gangguan sekresi hormon atau penggunaan glukosa yang tidak adekuat pada tingkat sel yang berdampak terhadap peningkatan kadar gula darah. Usia 50 tahun keatas akan terjadi peningkatan $5-10 \mathrm{mg} / \mathrm{dL}$ setiap tahun (Rantung et al., 2015 dalam Adimuntja, 2017). Menurut Riskesdas, 2018, bahwa prevalensi diabetes mellitus meningkat dengan bertambahnya usia hingga prevalensi tertinggi pada kelompok usia 55-64 tahun sebanyak 6,3\%.

Berdasarkan hasil uji chi square didapatkan $\mathrm{p}$ value > a maka $\mathrm{Ho}$ diterima. Hal ini menunjukkan bahwa tidak terdapat hubungan yang signifikan antara usia dengan pemberdayaan diri pasien diabetes melitus ( $p$ value $=0,796$, $a=0,05)$. Penelitian ini tidak sejalan dengan penelitian yang dilakukan Tol, et all, (2012) dalam Nuari (2014), yang berjudul faktor yang mempengaruhi diabetes empowerment di Iran, didapatkan hasil diabetes empowerment mempunyai hubungan dengan usia $(p<0,001)$. Penelitian tersebut menyatakan usia mempunyai hubungan signifikan dengan aspek penilaian ketidakpuasan dan kesiapan untuk berubah yang terdapat pada Diabetes Empowerment Scale (DES).

Hasil analisis peneliti, bahwa faktor usia tidak menentukan kemampuan individu untuk mempunyai kontrol sendiri terhadap keputusannya memilih yang terbaik untuk menyelesaikan masalah kesehatannya. Menurut Nuari, 2014, individu dengan usia lansia akan mempengaruhi kemampuan kognitif dalam menganalisis pilihan yang terbaik bagi kesehatannya dan mempunyai kemampuan fisik yang terbatas bila mencari perawatan ke fasilitas kesehatan dan tenaga Kesehatan.

3. Hubungan Pendidikan dengan Pemberdayaan Diri pada Pasien Diabetes Mellitus

Hasil penelitian ini menunjukkan bahwa sebagian besar responden memiliki pendidikan sekolah dasar (SD) yaitu sebanyak 14 orang $(43,8 \%)$. Penelitian ini sejalan dengan penelitian yang telah dilakukan Nuari, 2014, bahwa sebagian besar responden memiliki pendidikan sekolah dasar (SD) sebanyak 15 orang $(46,8 \%)$.

Namun pernyataan berbeda menurut Riskesdas, 2018, bahwa proporsi penderita diabetes mellitus cenderung lebih tinggi pada kelompok dengan pendidikan tamat akademi/ universitas yaitu sebesar 2,8\%. Hal ini dapat diasumsikan terkait dengan gaya hidup dan akses terhadap deteksi kasus di pelayanan kesehatan pada kelompok dengan tingkat pendidikan akademi/ universitas. 
Berdasarkan hasil uji chi square didapatkan $\mathrm{p}$ value < a maka Ho ditolak. Hal ini menunjukkan bahwa terdapat hubungan yang signifikan antara tingkat pendidikan dengan pemberdayaan diri pasien diabetes melitus $(p$ value $=0,006, \alpha=0,05)$. Penelitian ini sejalan dengan penelitian yang telah dilakukan oleh Nuari, (2014), bahwa pendidikan mempunyai hubungan signifikan dengan pemberdayaan diri dengan kekuatan hubungan kuat dan positif. Hal ini dapat diartikan bahwa semakin tinggi pendidikan seseorang maka mempunyai yang pemberdayaan diri semakin baik. Hasil analisis peneliti, semakin tinggi tingkat pendidikan semakin tinggi pula pemberdayaan diri. Pendidikan tinggi lebih cepat menyerap informasi, lebih aktif dalam mencari informasi kesehatan melalui media sosial, media cetak ataupun elektronik serta informasi dari petugas kesehatan lainnya. Sesuai dengan teori yang dinyatakan Julaiha, 2019, dalam Robiah, F. \& Fajriyah, N. N., 2020, pendidikan mempengaruhi daya serap seseorang dalam menerima informasi sehingga dapat mempengaruhi tingkat pemahaman tentang penyakit diabetes melitus. Pemahaman yang baik diharapkan meningkatkan pemberdayaan diri sehingga dapat memutuskan masalah kesehatannya. Sesuai dengan teori yang dinyatakan oleh Mola, 2008, dalam Rochfort, 2015, pemberdayaan diri merupakan proses pendidikan untuk membantu atau mendukung diri klien untuk mengembangkan pengetahuan, keterampilan, sikap dan kesadaran diri, dan untuk memikul tanggung jawab yang efektif untuk keputusan yang berhubungan dengan kesehatan.

\section{Hubungan Lama Menderita Diabetes Mellitus dengan Pemberdayaan Diri pada Pasien Diabetes Mellitus}

Hasil penelitian ini menunjukkan bahwa sebagian besar responden memiliki lama menderita diabetes mellitus 5 s.d 10 tahun. Penelitian ini tidak sejalan dengan penelitian yang telah dilakukan Nuari, 2014 bahwa sebagian besar responden memiliki lama menderita diabetes mellitus 1-5 tahun sebanyak 21 orang $(65,6 \%)$. Menurut Smeltzer \& Bare (2004) dalam Nuari, 2015, menyatakan diabetes melitus tipe 2 merupakan jenis diabetes melitus yang paling banyak jumlahnya yaitu sekitar 90-95\% dari seluruh penderita diabetes melitus dan banyak dialami oleh usia dewasa diatas 40 tahun. Hal ini disebabkan resistensi insulin pada diabetes melitus tipe 2 cenderung meningkat pada usia lansia (40-65 tahun). Faktor resiko lainnya yang berhubungan dengan proses terjadinya diabetes mellitus tipe II yaitu usia, obesitas, riwayat diabetes mellitus dan keluarga (Nurarif, 2015).

Berdasarkan hasil uji chi square didapatkan $\mathrm{p}$ value $>$ a maka Ho diterima. Hal ini menunjukkan bahwa tidak terdapat hubungan yang signifikan antara lama menderita diabetes melitus dengan pemberdayaan diri pasien diabetes melitus ( $p$ value $=0,151$, $a=0,05)$. Penelitian ini tidak sejalan dengan Nuari, 2014, yang menunjukkan bahwa lama menderita diabetes melitus mempunyai hubungan signifikan dengan self empowerment. Hal ini dapat diasumsikan bahwa semakin lama penderita diabetes melitus mengidap penyakit tersebut maka semakin rendah kesiapan individu untuk berubah. Individu merasa terbiasa dengan penyakitnya karena telah terjadi proses 
adaptasi yang cukup lama sehingga cenderung kurang sensitif menerima perubahan terhadap dirinya. Menurut Triyanto, E., dkk. 2015, pasien yang baru juga masih rendahnya pengetahuan mengenai penyakit diabetes melitus dan pengobatannya. Mereka mempunyai rasa ingin tahu yang besar. Lama waktu menderita DM berkaitan juga dengan penurunan fungsi sel beta pankreas, sehingga menimbulkan komplikasi yang terjadi pada pasien dengan lama sakit 5-10 tahun. Hal ini dapat dimungkinkan beberapa pasien dengan lama menderita lebih dari 5 tahun telah terjadi komplikasi. Hasil analisis peneliti, faktor lama menderita diabetes melitus ini, bukan faktor yang menentukan pemberdayaan penderita diabetes melitus baik atau kurang. Pemberdayaan yang baik tergantung pada kesiapan individu untuk berubah dan mampu mengontrol hidup mereka sendiri. Menurut Anderson et all, 2003, dalam Nuari 2014, pemberdayaan diri merupakan kemampuan seseorang dalam mengontrol hidup mereka sendiri dan menentukan pilihan mengenai kesehatan. Penderita diabetes mellitus mempunyai tanggung jawab untuk mengatur dirinya sendiri dalam melakukan perawatan pada penyakitnya.

\section{Hubungan Pengetahuan dengan Pemberdayaan Diri pada Pasien Diabetes Mellitus}

Hasil penelitian yang telah dilakukan peneliti terhadap pasien diabetes mellitus bahwa sebagian besar pengetahuan responden baik sebanyak 19 orang $(59,4 \%)$ dan kurang baik sebanyak 13 orang (40,6\%). Dapat disimpulkan bahwa pengetahuan responden sebagian besar yaitu baik. Pengetahuan merupakan hasil pengindraan manusia, serta hasil dari tahu seseorang terhadap objek melalui indra penglihatan, penciuman, pendengaran dan sebagainya, dengan sendirinya menghasilkan pengetahuan, hal tersebut sangat dipengaruhi oleh intensitas perhatian dan persepsi terhadap objek (Notoatmodjo, 2014). Pengetahuan dapat diperoleh dari berbagai sumber, diantaranya pendidikan atau edukasi, media cetak atau elektronik, lingkungan sosial dan sebagainya, sehingga dapat menambah pengetahuan.

Berdasarkan hasil uji chi square didapatkan $\mathrm{p}$ value > a maka Ho diterima. Hal ini menunjukkan bahwa tidak terdapat hubungan yang signifikan antara pengetahuan dengan pemberdayaan diri pasien diabetes melitus ( $p$ value $=0,450, \alpha=0,05$ ). Hasil penelitian ini sejalan dengan penelitian lain yang berbeda variable yaitu penelitian Wadja, H., dkk, 2018, yang berjudul Faktor-Faktor yang Berhubungan dengan Kejadian Diabetes Mellitus di UPTD Diabetes Center Kota Ternate, menunjukkan bahwa tidak ada hubungan yang bermakna antara tingkat pengetahuan dengan kejadian diabetes mellitus di UPTD Diabetes Center Kota Ternate ( $\mathrm{p}$-value $0,709>0,1)$.

Menurut analisis peneliti, tidak ada hubungannya antara pengetahuan baik lebih tinggi dari pengetahuan kurang terhadap pemberdayaan diri diabetes mellitus, berdasarkan hasil penelitian ini dikarenakan ada faktor lain yang mempengaruhi yaitu pendidikan. Seseorang yang berpendidikan, mampu mengambil keputusan terhadap masalah kesehatannya dan menerapkan pola hidup yang sehat seperti tidak lagi mengkonsumsi makanan yang mengandung banyak gula. 
Pengetahuan tentang penyakit diabetes mellitus sangat penting karena tidak hanya untuk memahami penyakit tersebut tetapi pasien diabetes melitus dapat menentukan langkah selanjutnya yang perlu diambil untuk mengurangi beratnya penyakit. Dengan pengetahuan manusia dapat mengembangkan apa yang diketahui dan dapat mengatasi kebutuhan kelangsungan hidup (Conceicao dkk, 2011, dalam Wadja, H, dkk, 2018). Suatu perilaku kesehatan dipengaruhi oleh tiga aspek, yaitu pengetahuan, sikap dan praktik atau tindakan. Pengetahuan atau kognitif merupakan domain yang sangat penting untuk terbentuknya tindakan seseorang (Notoatmodjo, 2007).

6. Hubungan Pendapatan dengan Pemberdayaan Diri pada Pasien Diabetes Mellitus

Hasil penelitian yang telah dilakukan peneliti terhadap pasien diabetes mellitus bahwa sebagian besar responden yang mempunyai pendapatan $<1$ juta yaitu 21 orang (65,6\%), sedangkan untuk pendapatan 1-3 juta yaitu 11 orang $(34,4 \%)$. Dapat disimpulkan bahwa sebagian besar responden yang mempunyai pendapatan < 1 juta. Menurut Setiawan, 2021, Upah Minimum Regional (UMR) Kabupaten Cirebon yaitu Rp 2.269.556. Berdasarkan status sosial ekonomi pasien diabetes melitus mayoritas berpenghasilan dibawah UMR. Hal ini sesuai dengan penelitian yang dilakukan oleh Nugroho, Ika \& Saekhol (2018) dalam Robiah, F. \& Fajriyah, N. N. 2020, dengan hasil penelitian menunjukkan status sosial ekonomi pasien diabetes melitus sebanyak 53 orang $(91,4 \%)$. Tingkat penghasilan yang rendah erat kaitannya dengan tanggung jawab dalam keluarga membuat perubahan dalam gaya hidup yang tidak sehat, termasuk dalam memilih makanan dan melakukan aktifitas.

Berdasarkan hasil uji chi square didapatkan $\mathrm{p}$ value > a maka Ho diterima. Hal ini menunjukkan bahwa tidak terdapat hubungan yang signifikan antara pendapatan dengan pemberdayaan diri pasien diabetes melitus ( $p$ value $=0,074$, $a=0,05)$. Hasil analisis peneliti, perbedaan pendapatan pasien diabetes melitus tidak mempengaruhi pemberdayaan seseorang dalam mencari perawatan dan pengobatan penyakit yang dideritanya.

\section{Hubungan Dukungan Keluarga dengan Pemberdayaan Diri pada Pasien Diabetes Mellitus}

Hasil penelitian yang telah dilakukan peneliti terhadap pasien diabetes mellitus bahwa sebagian besar dukungan keluarga responden baik sebanyak 23 orang $(71,9 \%)$ dan kurang baik sebanyak 9 orang $(28,1 \%)$. Dapat disimpulkan bahwa dukungan keluarga responden sebagian besar yaitu baik. Penelitian ini sejalan dengan penelitian lain yang dilakukan Susanti, M.L., dkk, 2013, yang berjudul Dukungan Keluarga Meningkatkan Kepatuhan Diet Pasien Diabetes Melitus di Ruang Rawat Inap RS Baptis Kediri, menunjukkan bahwa sebagian besar dukungan keluarga responden baik sebanyak 17 orang (68,0\%). Dapat disimpulkan bahwa dukungan keluarga responden sebagian besar yaitu baik. Perawatan diabetes mellitus sangat membutuhkan keterlibatan keluarga sejak terdiagnosa penyakit diabetes mellitus. Dukungan keluarga memberikan dampak positif terhadap perawatan diri pada pasien 
diabetes melitus (Hensarling, 2009 dalam Yusra, 2011).

Berdasarkan hasil uji chi square didapatkan $\mathrm{p}$ value $>$ a maka Ho diterima. Hal ini menunjukkan bahwa tidak terdapat hubungan yang signifikan antara dukungan keluarga dengan pemberdayaan diri pasien diabetes melitus ( $p$ value $=0,213, a=0,05)$. Hasil penelitian ini sejalan dengan penelitian lain dengan variable berbeda yaitu hasil penelitian Nugroho, dkk, 2018, dalam Robiah, F. \& Fajriyah, N. N. 2020, menunjukkan bahwa dukungan keluarga tidak berpengaruh terhadap kepatuhan menjalankan pengobatan, tetapi dukungan keluarga berpengaruh dengan kadar glukosa darah. Hasil penelitian ini tidak sejalan dengan penelitian lain dengan variabel berbeda yaitu penelitian yang dilakukan Susanti, M.L., 2013, yang berjudul Dukungan Keluarga Meningkatkan Kepatuhan Diet Pasien Diabetes Mellitus Di Ruang Rawat Inap RS. Baptis Kediri, didapatkan hasil dukungan keluarga dapat meningkatkan kepatuhan diet pada pasien Diabetes Mellitus di RS. Baptis Kediri $(p \leq 0,05)$.

Hasil analisis peneliti, keterlibatan keluarga dalam melakukan perawatan pasien diabetes melitus sebagai bentuk dukungan keluarga. Namun, faktro ini tidak mempengaruhi pemberdayaan diri. Pemberdayaan diri tergantung pada kemampuan diri untuk memilih fasilitas kesehatannya. Dukungan keluarga merupakan bagian dari pemberdayaan keluarga. Sesuai dengan teori yang dinyatakan (Gomes et all., 2017, dalam Rasnah, dkk, 2019) pemberdayaan keluarga sebagai pendamping perawatan penderita diabetes melitus dalam program pengelolaan kesehatan, khususnya bagi mereka yang dapat mempromosikan berbagai bentuk dukungan sosial dalam kontrol penyakit, pencegahan komplikasi serius karena kontrol yang buruk dan memperkuat ikatan antara anggota keluarga.

\section{KESIMPULAN DAN SARAN}

Hasil penelitian menggambarkan bahwa terdapat hubungan signifikan dalam faktor pendidikan dan sedangkan faktor yang tidak mempunyai hubungan yang signifikan adalah jenis kelamin, usia, lama menderita diabetes melitus, pengetahuan, pendapatan dan dukungan keluarga.

Saran dalam penelitian ini adalah penelitian ini dapat dijadikan data dasar penelitian selanjutnya. Peneliti selanjutnya dapat memberikan edukasi yang dapat meningkatkan pemberdayaan diri pasien diabetes melitus.

\section{DAFTAR PUSTAKA}

Adimuntja, N.P. (2017). Analisis Faktor yang Berhubungan dengan Aktifitas Self Care Diabetes pada Pasien Diabetes Melitus Tipe 2 Di RSUD Labuang Baji Kota Makasar. Tesis Program Pascasarjana Universitas Hasanudin Makasar.

Black, J. M. \& Hawk H. M. (2014). Keperawatan Medikal Bedah Manajemen Klinis untuk Hasil yang Diharapkan. Singapore : Elsevier.

Ho, A. Y. K, et all. (2010). Diabetes empowerment related to Pender's HealthPromotion Model:A meta-synthesis. Nursing and Health Sciences (2010), 12, 259-267. at: https: / /www.researchgate.net/ publication/45093758 
International Diabetes Federation. (2019). IDF Diabetes Atlas Seventh Edition 2019. www.diabetesatlas.org

Kementrian Kesehatan RI. (2019). Situasi dan Analisis Diabetes. Jakarta Selatan : Infodatin Pusat Data dan Informasi Kementrian Kesehatan RI.

Lemone, E. Et all. (2016). Buku Ajar Keperawatan Medikal Bedah Vol. 2 Edisi 5. Jakarta: EGC.

Notoatmodjo, S. (2007). Kesehatan Masyarakat: Ilmu \& Seni. Jakarta : Rineka Cipta. . (2014). Ilmu Perilaku Kesehatan. Jakarta : Rineka Cipta.

Nuari, N. A. (2014). Analisis Korelasi Personal Factor, Perceived Benefit Dan Perceived Barrier Dengan Pemberdayaan Diri Pasien Diabetes Mellitus Tipe Ii Berbasis Teori Health Promotion Model. Jurnal Gaster Vol. XI No. $2 \quad$ Agustus 2014. http://download.portalgaruda.o rg/article.php.

Nuari, N. A. \& Kartikasari, M. (2015). Peningkatan Self Empowerment dan Kualitas Hidup Pasien Diabetes Melitus Tipe II dengan Pendekatan DEE Berbasis Health Promotion Model. http://ejournal.unair.ac.id/index.php/J NERS/article/view/14/1097.

Nurarif, A. H. \& Kusuma, H. (2015). Aplikasi Asuhan Keperawatan berdasarkan Diagnosa Medis dan NANDA NIC-NOC Jilid 1. Jogjakarta : Mediaction.

Rasnah, dkk. (2019). Efektifitas Pemberdayaan Keluarga Terhadap Kontrol Metabolik pada Pasien Diabetes Melitus Tipe 2. Jurnal Keperawatan Muhammadiyah 4 (2) 2019. http://journal.um.surabaya.ac.i d/index.php/JKM.

Riset Kesehatan Dasar. (2018). Badan Penelitian dan Pengembangan
Kesehatan Kemenkes RI Tahun 2018.

Rochfort, A. (2015). Patient Empowerment for Patient SelfManagement Wonca Europe 20th Anniversary Project 2015. The World Book of Family Medicine European Edition 2015. www. woncaeurope.org.

Robiah, F \& Fajriyah, N. N. (2020). Literatur Review: Faktor-faktor yang Mempengaruhi Kepatuhan Kunjungan Berobat Pasien Diabetes Melitus Untuk Pengendalian Kadar Glukosa Darah. Program Sarjana Keperawatan Universitas Muhammadiyah Pekajangan Pekalongan.

Setiawan. (2021). Daftar Besarnya Upah Minimum Regional (UMR) Cirebon Dari 2021. https://upahminimum.com/umr -cirebon-terbaru.html.

Susanti, M.L., (2013). Dukungan Keluarga Meningkatkan Kepatuhan Diet Pasien Diabetes Mellitus Di Ruang Rawat Inap RS. Baptis Kediri. Jurnal STIKES Volume 6, No. 1, Juli 2013. https://media.neliti.com/media /publications/210340-none.pdf.

Suyono, S. dkk. (2015). Penatalaksanaan Diabetes Mellitus Terpadu. Jakarta : Fakultas Kedokteran Universitas Indonesia.

Tarwoto, dkk. (2012). Keperawatan Medikal Bedah Gangguan Sistem Endokrin. Jakarta : TIM.

Tol, A. Et all. (2013). Empowerment Assessment And Influential Factors Among Patients With Type 2 Diabetes. Journal of Diabetes \& Metabolic Disorders 2013, 12:6. http://www.jdmdonline.com/co ntent $/ 12 / 1 / 6$

Triyanto, E. dkk. 2015. Model Pemberdayaan Terpadu untuk Meningkatkan Kepatuhan Pasien Diabetes Melitus. JURNAL MKMI, 
Desember 2015, hal. 228-234. Program Studi Keperawatan Fakultas Ilmu-Ilmu Kesehatan Universitas Jenderal Soedirman.

Wadja, H., dkk, 2018. Faktor-faktor yang Berhubungan dengan Kejadian Diabetes Melitus di UPTD Diabetes Center Kota Ternate Tahun 2018. Jurnal BIOSAINSTEK. Vol. 1 No. 1, 38-45. http://www.jurnal.ummu.ac.i/i ndex.php/BIOSAINSTEK

Wong \& Riege. (2012). Patient Empowerment- Living with
Chronic

Disease. www.careum.ch.

Yusra, A. (2011). Hubungan antara Dukungan Keluarga dengan Kualitas Hidup Pasien Diabetes Melitus Tipe 2 Di Poliklinik Penyakit Dalam Rumah Sakit Umum Pusat Fatmawati Jakarta. Tesis Magister Ilmu Keperawatan Universitas Indonesia. http: / / lib.ui.ac.id/file?file=digit al/20280162-

T\%20Aini\%20Yusra.pdf 